\title{
Variação da cobertura vegetal com ênfase na identificação de mancha de cerrado em um perfil topográfico do semiárido pernambucano - Brasil
}

\author{
Changes in vegetation coverage with emphasis on the identification \\ of cerrado patches in a topographic profile of the semi-arid region \\ from Pernambuco - Brazil
}

\author{
Linaldo Severino dos Santos ${ }^{1}$ \\ Hewerton Alves da Silva ${ }^{2}$ \\ Eugênia C. Pereira ${ }^{3}$ \\ Helena Paula de B. Silva ${ }^{4}$
}

Palavras-chave:
Cobertura vegetal
Mancha de cerrado
Perfil topográfico
Semiárido de Pernambuco

Keywords:

Vegetation coverage

Cerrado patches

Topographic profile

Semi-arid region of

Pernambuco

\begin{abstract}
Resumo
O semiárido nordestino é uma das regiões brasileiras mais desconhecidas, no tocante à diversidade vegetacional, uma vez que são propagadas, injustamente, informações que versam sobre as poucas plantas endêmicas da Caatinga. Entretanto, apesar desse bioma ter sofrido bastante pela ação antrópica, este apresenta uma grande diversidade de tipos vegetacionais, inclusive apresentando disjunções de outros biomas em áreas de exceção, como ocorrem nos brejos de altitude, que de maneira pontual estão presentes na paisagem do semiárido nordestino. Com isso, neste estudo buscou-se realizar uma análise no sentido da diferenciação da cobertura vegetal ao longo de um perfil topográfico, em recorte espacial do agreste meridional pernambucano, compreendendo porções dos municípios de Águas Belas, Iati e Saloá, através das dez parcelas instaladas ao longo desse perfil. A aplicação do Índice de Vegetação por Diferença Normalizada (NDVI) mostrou a variação dos valores em função da topografia, revelando que nas áreas de depressão, em que se observa uma caatinga mais seca, obteve-se o menor valor do NDVI $(0,18)$. Em contrapartida, nas áreas de relevo mais elevado, onde se desenvolvem matas serranas e o cerrado, foram encontrados os maiores valores $(0,49)$, mostrando, desta forma, a influência da topografia na distribuição da umidade e feições vegetacionais.
\end{abstract}

\footnotetext{
${ }^{1}$ Programa de Pós-graduação em Geografia, Universidade Federal de Pernambuco. linaldo.geo@gmail.com 2Universidade Federal de Campina Grande. hewasupe@gmail.com

${ }^{3}$ Programas de Pós-Graduação em Geografia, e de Biologia vegetal, Universidade Federal de Pernambuco. verticillaris@gmail.com

${ }^{4}$ Universidade de Pernambuco. helena.silva@upe.br
} 
exceptional areas, such as humid brejos de altitude, which are present as isolated patches in the landscape of the semi-arid Northeast. Thus, in this study, an analysis was made to differentiate the vegetation coverage along a topographic profile, in a spatial transect of the southern Agreste region of Pernambuco, comprising portions of the municipalities of Águas Belas, Iati and Saloá, through 10 plots established along this topographic profile. Application of the Normalized Difference Vegetation Index (NDVI) showed the variation of values as a function of the topography, revealing that in depression areas, where drier caatinga is observed, the lowest value of NDVI was obtained (0.18). On the other hand, in the areas of higher relief, where montane forests and cerrado develop, the highest values were found (0.49), thus showing the influence of topography on the distribution of humidity and vegetational features.

\section{INTRODUÇÃO}

O estabelecimento de manchas de cerrado no semiárido nordestino se dá primordialmente devido ao fator altitude. Em estudo preliminar sobre identificação de uma mancha de cerrado no município de Saloá, agreste meridional de Pernambuco - Brasil, que coincide com o recorte espacial selecionado para este estudo, Santos et al. (2014) associam essa mancha com a fitofisionomia de cerrado stricto senso. Ribeiro e Walter (2008), ressaltam que são encontrados nesse ambiente indivíduos baixos, tortuosos, inclinados, com ramificações irregulares e retorcidos. Desta forma, essas manchas se traduzem como fragmentos que, devido às variações no gradiente topográfico e nos fatores edáficos, formam uma área de ecótono, interligando diferentes feições de solo e vegetação. Neste sentido, necessitam de estratégias singulares para conservação desses remanescentes, bem como a recuperação de áreas degradadas.

Nesse sentido, o objetivo deste estudo foi identificar e caracterizar a variação da vegetação que se desenvolve ao longo do perfil topográfico em áreas de transição entre o semiárido e o agreste Meridional de Pernambuco, com ênfase na identificação da composição florística do enclave de cerrado que se estabeleceu no topo do Brejo de Saloá, compreendendo porções dos municípios de Águas Belas, Iati e Saloá.

\section{MATERIAL E MÉTODOS}

\section{Área de estudo}

A área está compreendida nos municípios de Águas Belas, Iati e Saloá, fazendo parte do
Agreste Meridional de Pernambuco (mapa 1). Os municípios de Águas Belas e Iati fazem parte da unidade geomorfológica depressão Interplanáltica do Alto Ipanema, enquanto o município de Saloá está localizado na Cimeira Estrutural Pernambuco-Alagoas (CORRÊA et al., 2010).

\section{Metodologia aplicada ao trabalho de campo}

Visitas a campo no mês de julho de 2013. Para tanto, o procedimento metodológico aplicado segue as recomendações do IBGE (2012). Nesse sentido, a técnica de amostragem adotada foi a Aleatória Restrita ou Estratificada, que consiste em estratificar uma determinada área florestal (população) em subpopulações homogêneas (estratos), com base na interpretação de fotografias aéreas ou outros sensores.

Para uma melhor operacionalização dos procedimentos de campo, adotou-se uma técnica metodológica complementar, para adaptação aos objetivos e condições que o estudo apresentou. Tal técnica é Avaliação Ecológica Rápida (AER) (SOBREVILLA; BATH, 1992), cuja utilização teve a função de coletar os dados qualitativos de forma rápida, embora exigindo uma analise prévia da área de estudo. $\mathrm{O}$ método AER se baseia em uma compreensão prévia da área da pesquisa, com base em bancos de dados, fotografias aéreas, imagens de sensoriamento remoto, mapas, para que se defina qual procedimento de campo será adotado. São coletadas espécies para identificação e deposição em herbário, e características físicas da área são anotadas. Após esse momento, todos os dados extraídos em campo receberam tratamento, a fim de fornecer ferramentas para uma análise das informações espaciais. Estas, através da AER podem gerar, de maneira sucinta, a descrição da vegetação, realizando 
o georreferenciamento de manchas de vegetação, a análise do estado de conservação da área de estudo, como também da lista das espécies coletadas. Este método, considerado flexível, apresenta rapidez, facilidade de aplicação e de análise de dados, possibilitando o trabalho com uma equipe reduzida de pesquisadores.

Mapa 1. Localização da área de estudo, municípios de Águas Belas, Iati e Saloá, Estado de Pernambuco - Brasil.

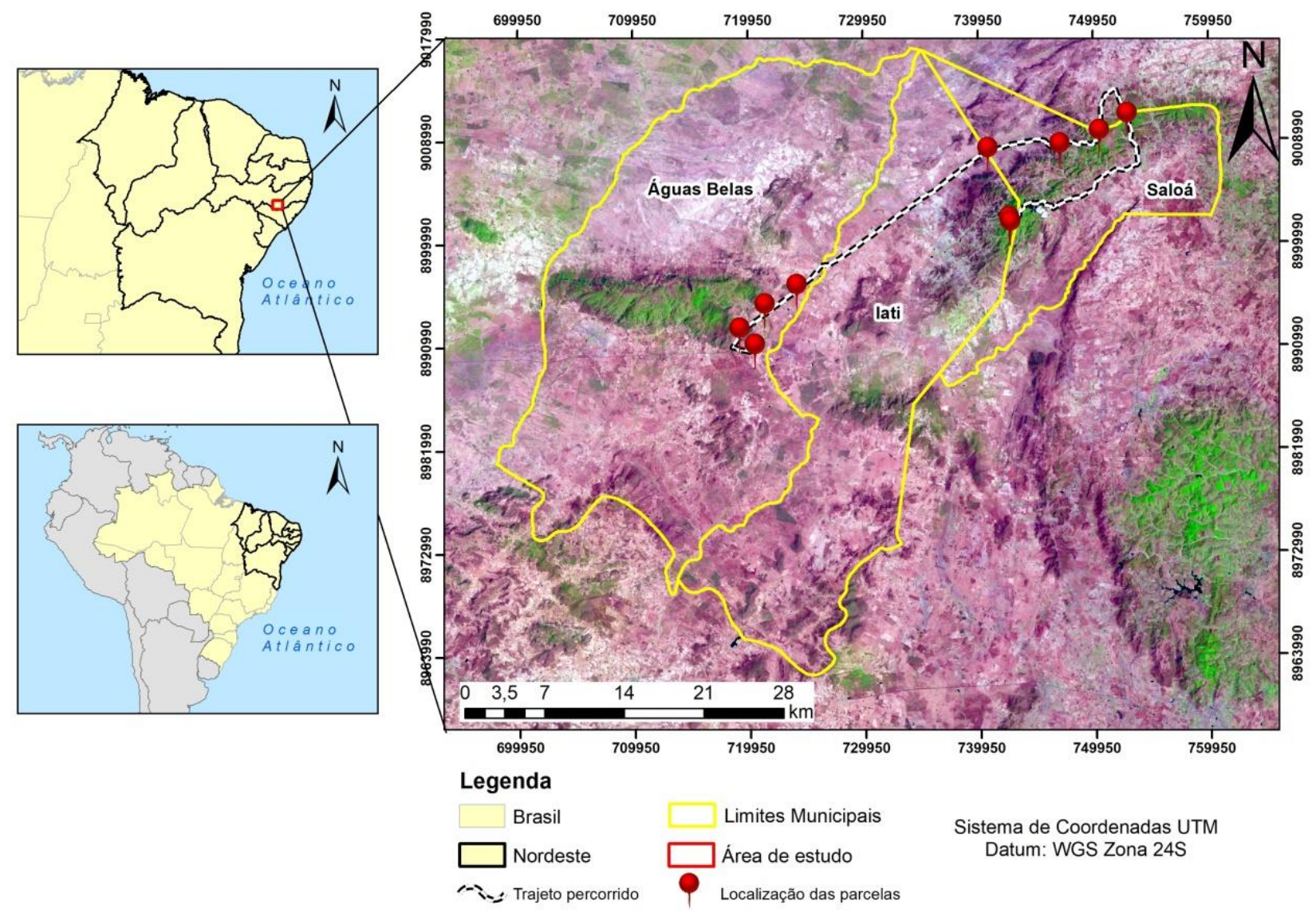

Fonte: Autores.

Aliando as duas técnicas metodológicas descritas no recorte espacial selecionado para a realização deste estudo foram instaladas dez parcelas com $30 \mathrm{~m}$ x $30 \mathrm{~m}$. Estas foram alocadas ao passo que havia mudanças significativas na composição da vegetação, como também no gradiente topográfico. Ressalta-se, também, que procurou-se instalar as parcelas nos locais onde apresentavam sua vegetação minimamente preservada. Deste modo, obedecendo a estes requisitos, não houve equidistância entre as parcelas, importando para a pesquisa as nuances encontradas ao longo do perfil de paisagem. As dez parcelas instaladas entre os municípios podem ser observadas no mapa 1 e suas localizações com respectivo georreferenciamento estão apresentadas na tabela 1 .

As parcelas foram distribuídas para realizar coletas botânicas, para contemplar as espécies dominantes em cada ambiente selecionado. Após as coletas, os espécimes foram levados para herbário a fim de identificá-los e depositá-los, com o objetivo de testar a hipótese da variação da estrutura da vegetação ao longo do perfil topográfico, como também da ocorrência da mancha de cerrado no topo desse perfil. Além disso, foi feito registro fotográfico para distinção de fisionomias vegetais, e georreferenciamento dos locais de coleta com uso de receptor GPS. 
Tabela 1. Coordenadas georreferenciadas, altitude e município dos pontos obtidos para a elaboração do perfil topográfico.

\begin{tabular}{ccccc}
\hline Parcelas & Latitude & Longitude & Altitude & Município \\
\hline 1 & $9.12426^{\circ} \mathrm{S}$ & $36.99365^{\circ} \mathrm{W}$ & $408 \mathrm{~m}$ & Águas Belas \\
\hline 2 & $9.11148^{\circ} \mathrm{S}$ & $37.00602^{\circ} \mathrm{W}$ & $457 \mathrm{~m}$ & Águas Belas \\
\hline 3 & $9.09237^{\circ} \mathrm{S}$ & $36.98561^{\circ} \mathrm{W}$ & $396 \mathrm{~m}$ & Águas Belas \\
\hline 4 & $9.07695^{\circ} \mathrm{S}$ & $36.96050^{\circ} \mathrm{W}$ & $394 \mathrm{~m}$ & Águas Belas \\
\hline 5 & $8.96851^{\circ} \mathrm{S}$ & $36.80968^{\circ} \mathrm{W}$ & $508 \mathrm{~m}$ & Iati \\
\hline 6 & $8.96523^{\circ} \mathrm{S}$ & $36.75299^{\circ} \mathrm{W}$ & $747 \mathrm{~m}$ & Saloá \\
\hline 7 & $8.95476^{\circ} \mathrm{S}$ & $36.72229^{\circ} \mathrm{W}$ & $965 \mathrm{~m}$ & Saloá \\
\hline 8 & $8.94136^{\circ} \mathrm{S}$ & $36.70044^{\circ} \mathrm{W}$ & $997 \mathrm{~m}$ & Saloá \\
\hline 9 & $9.02343^{\circ} \mathrm{S}$ & $36.79278^{\circ} \mathrm{W}$ & $1090 \mathrm{~m}$ & Saloá \\
\hline 10 & $9.02673^{\circ} \mathrm{S}$ & $36.79199^{\circ} \mathrm{W}$ & $1052 \mathrm{~m}$ & Saloá \\
\hline
\end{tabular}

Fonte: Autores.

\section{Índice de vegetação por diferença normalizada (NDVI) e suas técnicas}

O NDVI é simples, fácil de ser implementado e pode ser efetivo na predição de propriedades da superfície, quando a copa da vegetação não é muito densa ou muito esparsa.

O NDVI é obtido através da equação:

$$
N D V I=\frac{(N I R-R)}{(N I R+R)}
$$

Em que: NIR e R são fatores de reflectância bidirecional espectrais (razão da radiância do alvo na superfície pela radiância de uma superfície conservativa, lambertiana) nos comprimentos de onda do visível (vermelho) e infravermelho próximo, respectivamente (MYNENI et al., 1995). São as reflectâncias da superfície no infravermelho próximo $(0,8 \mu \mathrm{m}$ a $1,1 \mu \mathrm{m})$ e no visível (vermelho $-0,6 \mu \mathrm{m}$ a $0,7 \mu \mathrm{m}$ ) (ASRAR et al., 1984).

Para a obtenção do NDVI no recorte espacial analisado, foram utilizadas imagens do sensor TM (Thematic Mapper), que se encontram a bordo do satelite Landsat 5, adquiridas junto ao Instituto Nacional de Pesquisas Espaciais INPE. As imagens utilizadas para a realização deste estudo foram obtidas em 10/12/2013.

As imagens foram empilhadas e ortorretificadas. A correção geométrica (ortorretificação) foi realizada de imagemimagem. Esse procedimento de correção se dá quando se toma como referência uma imagem cuja geometria já esteja corrigida, para corrigir outra imagem. Essa etapa é de fundamental importância, uma vez que as imagens obtidas apresentam distorções em relação ao terreno. $\mathrm{O}$ processamento das imagens foi realizado utilizando o programa ERDAS Imagine versão 9.3 licenciado no Laboratório de Geoprocessamento e Sensoriamento Remoto SERGEO do Departamento de Ciências Geográficas da UFPE, com a ferramenta Model Maker.

\section{RESULTADOS E DISCUSSÃO}

Aplicações do Índice de Vegetação NDVI (Normalized Difference Vegetation Index) e Perfil Topográfico

A partir da análise do índice de vegetação NDVI ( mapa 2), foi possível realizar uma série de correlações decorrentes dos dados encontrados.

Nesse sentido, torna-se relevante a comparação com outros trabalhos com relação aos valores das classes de NDVI, sobretudo aos valores encontrados para o cerrado. Em trabalho realizado no município de Santa Rita do Passa Quatro, estado de São Paulo, sobre diferenciação de fisionomias de cerrado utilizando índice de vegetação, Bitencourt et al. (1997) constataram os seguintes valores: para a fisionomia campo sujo o NDVI de 0,02 a 0,20; campo úmido de 0,02 a 0,20 ; campo cerrado de 0,20 a 0,26 ; cerrado sensu stricto de 0,26 a 0,38 ; cerrado sensu stricto tendendo a cerradão de 0,38 a 0,44 ; cerradão de 0,44 a 0,55 e mata mesófila de 0,44 a 0,55 . 
Mapa 2. Índice de vegetação por diferença normalizada (NDVI), em destaque os pontos 1-10 que representam as parcelas instaladas na área de estudo.

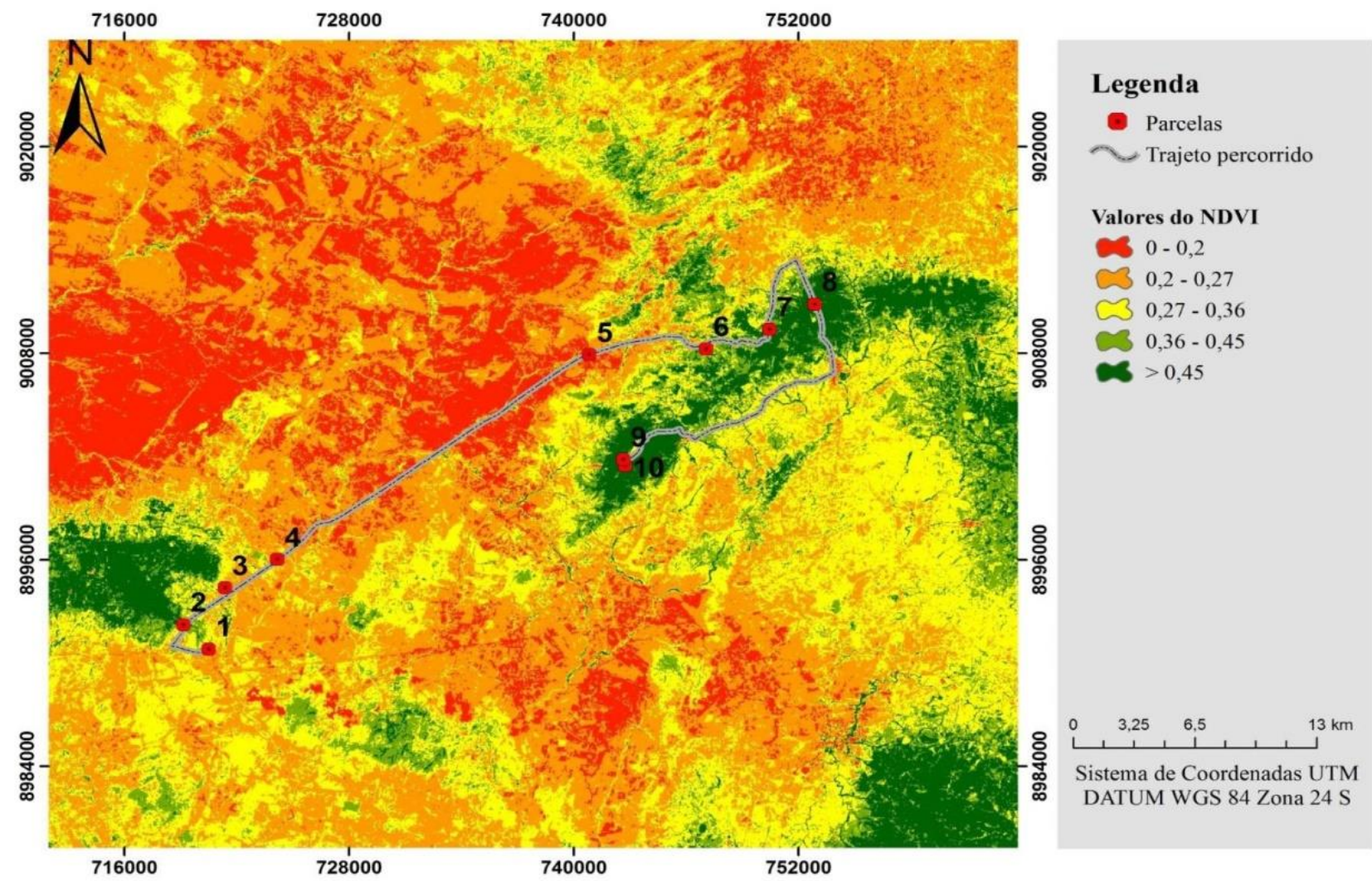

Fonte: Autores.

Carvalho Júnior et al. (2008), em estudo sobre classificações de padrões de savanas utilizando índice de vegetação na Chapada dos Veadeiros, estado de Goiás, encontraram valores de NDVI tanto para períodos secos quanto para períodos chuvosos nas seguintes fisionomias de cerrado: para o ambiente de cerrado denso foi encontrado o valor médio do NDVI de 0,8 para o período chuvoso e, 0,62 para o período seco; para o ambiente com predomínio de campo de 0,60 para o período chuvoso e, 0,35 para o período seco. No ambiente composto pelo cerrado ralo ou rupestre de 0,60 na época de chuva e 0,4 no período de estiagem.

Os valores de NDVI encontrados para o enclave de cerrado no topo do brejo de Saloá, está representado pelas parcelas 9 e 10, apresentando valores próximos aos encontrados em áreas de cerrado, inclusive as áreas de cerrado do Brasil central.

Contudo, é necessário ressaltar que a variação dos valores do índice de vegetação pode ser explicada pela diferença da diversidade florística e complexidade estrutural em cada fisionomia, pois as correlações entre os estratos herbáceos, arbustivos e arbóreos do cerrado desencadeiam importantes variações nos parâmetros biofísicos (ASNER; WARNER, 2003). Desta forma, torna-se limitada a padronização de determinada fisionomia do cerrado ou de outro bioma de acordo com os valores obtidos através do NDVI, pois tal determinação depende de vários parâmetros como o clima, o tipo, uso e exposição do solo, dentre outros aspectos.

Uma análise bastante pertinente é a interpretação dos valores de densidade da vegetação obtidos a partir do NDVI, confrontados com os valores altimétricos de todas as dez parcelas trabalhadas (gráfico $1)$. 
Gráfico 1. Valores de altitude e NDVI por parcela na área de estudo, municípios de Águas Belas, Iati e Saloá, Agreste Meridional de Pernambuco - Brasil.

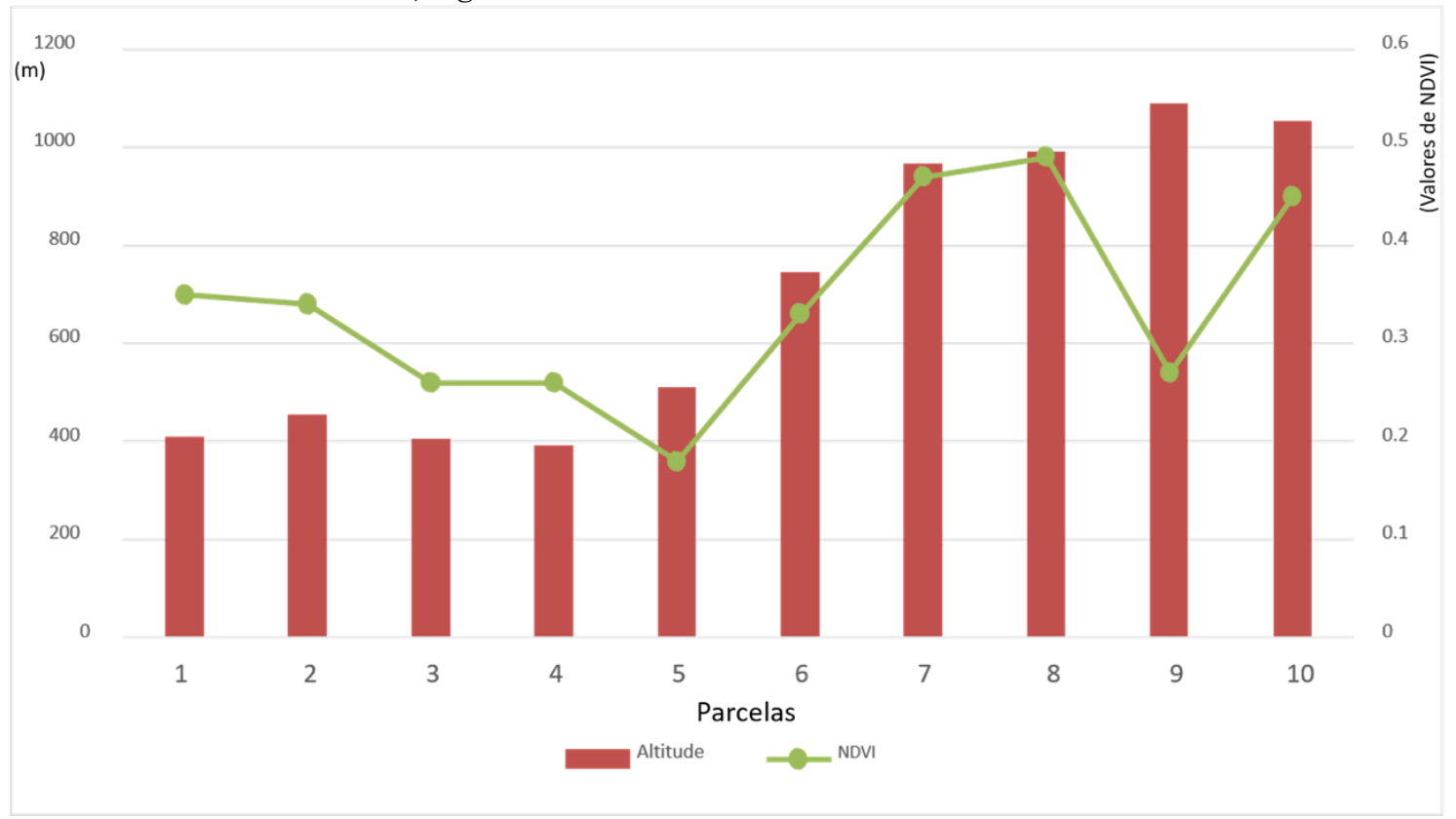

Fonte: Autores.

A correlação detalhada e individualizada por parcela explica, entre outros aspectos, as oscilações contidas na correlação dos valores do NDVI com as cotas altimétricas, e influência de outros fatores físicos. A parcela 1 corresponde a um recorte no município de Águas Belas, e apresenta altitude de 408 metros. A área é coberta por um fragmento de caatinga arbórea densa localizada em uma encosta. Para esta área o NDVI teve valor de 0,35 , sendo considerado um índice relativamente alto, principalmente por estar inserida na depressão sertaneja, onde a vegetação dominante é uma caatinga mais seca. Contudo, o valor alto pode ser explicado pelo fato de que a posição desta parcela foi relativamente próximo ao Brejo de Águas Belas, com condições de umidade mais elevadas do que a caatinga que a circunda, favorecendo a formação vegetal caatinga arbórea densa, com valores de densidade superiores em relação a outras formações vegetais.

A segunda parcela também fica localizada no município de Águas Belas, marcando uma altitude de 457 metros. A parcela foi alocada em uma área de caatinga arbustiva densa. Contudo, a área é influenciada por atividades agropastoris. O valor do NDVI para esta parcela é de 0,34 , relativamente alto para o padrão da depressão sertaneja. Este fato pode ser explicado pela proximidade ao Brejo de Águas Belas, assim como no caso da primeira parcela, como também pela própria densidade da caatinga arbustiva local.

A terceira parcela também foi instalada no município de Águas Belas em uma altitude de 396 metros. A formação vegetal do local analisado é uma caatinga com grande presença de estruturas vegetacionais, arbustiva e herbácea. Com relação ao NDVI, esta parcela apresentou um valor em torno de 0,26 , cujo índice é explicado pela própria fisionomia da vegetação, que não se mostra com um alto adensamento. É possível que se observem essas variações em virtude de existir diminuição da umidade com relação às duas primeiras parcelas. Apesar de não haver estudo microclimático para a área, é possível se inferir tal premissa, visto que a umidade reflete diretamente no adensamento da vegetação.

Ainda no município de Águas Belas, a quarta parcela foi instalada. Esse ponto marca 394 metros de altitude, não variando significantemente com relação às parcelas anteriores. O valor do NDVI para esta área marcou 0,26, não se apresentando elevado, sendo o reflexo da cobertura vegetal, que se mostra como uma caatinga arbórea notadamente espaçada.

No município de Iati foi instalada a quinta parcela, com altitude de 508 metros. A fisionomia da cobertura vegetal permaneceu como sendo de uma caatinga típica de ambiente seco, onde o estrato arbustivo prevalece. A vegetação deste ambiente divide espaço e sofre bastante com a atividade agropastoril que é 
exercida na região, apresentando várias áreas degradadas. Este fato influenciou no NDVI, que registrou o menor valor com relação a todas as parcelas $(0,18)$, revelando que neste ambiente a vegetação se mostra pouco densa.

A sexta parcela foi instalada no município de Saloá, onde a altitude atingiu 747 metros, repercutindo de maneira preponderante na fisionomia da vegetação. A cobertura vegetal da área é predominantemente arbórea, com alguns elementos da caatinga e do cerrado, apresentando-se como uma formação de mata serrana. Em relação ao NDVI, ela apresentou um valor de 0,33. Teoricamente esta parcela deveria ter um NDVI superior aos demais. No entanto, segundo registros da vegetação, ela se conFigura como área de transição, comportando feições de cerrado e de caatinga. Dessa forma, apresenta áreas espaçadas, explicando o baixo NDVI, quando comparado às parcelas 1 e 2 . Nóbrega et al. (2012) estudaram, para bioprospecção e biotecnologia, o líquen Parmotrema andinum, coletado nessa mesma área. Esta espécie, até o mencionado estudo, era apenas registrada para o cerrado do Centrooeste brasileiro, o que corrobora nossos achados.

A sétima parcela foi alocada no município de Saloá. A altitude registrada para esse ponto foi de 965 metros, repercutindo de forma decisiva na conFiguração e desenvolvimento da cobertura vegetal. Apresenta-se como uma formação de mata serrana, se destacando em sua exuberância e porte arbóreo. A densidade e exuberância da cobertura vegetal são refletidas no NDVI, que registrou o valor de 0,47 para este ponto.

Com uma altitude de 997 metros, a parcela 08 foi alocada no município de Saloá. A cobertura vegetal da área analisada se caracteriza como uma mistura entre os estratos arbustivo e arbóreo, chamando a atenção para sua exuberância e alta densidade, sendo responsável pelo maior valor de NDVI encontrado $(0,49)$. A área tem caráter ecotonal, apresentando espécies típicas de mata serrana, caatinga e cerrado. Entretanto, nas partes superiores do perfil, a unidade de solo vai se tornando cada vez mais arenosa (areias quartzosas), o que facilita a penetração e percolação da água. Nas partes cimeiras dos brejos há maior umidade, no entanto, um solo que facilite a percolação pode sugerir à planta uma condição de falsa seca, o que é típico em cerrados edáficos.

As duas últimas parcelas (09 e 10) merecem uma análise integrada, pois se trata do mesmo ambiente. Tais parcelas foram instaladas no topo do gradiente topográfico, no município de Saloá, com altitudes que marcam 1090 e 1052 metros, respectivamente. A vegetação destas parcelas se apresentam como uma verdadeira disjunção do cerrado, com espécies típicas daquele bioma, cuja altitude somada a alta umidade, um clima ameno e características do solo, propiciam condições para que tal mancha de cerrado se estabeleça nesse ambiente. Contudo, nessa área não só ocorrem espécies de cerrado; elementos da caatinga também estão presentes, formando um ambiente ecotonal. Liquens terrícolas da família Cladoniacae, que ocorrem naturalmente sobre solos arenosos de cerrados climáticos e edáficos (PEREIRA et al., 2019), inclusive na na Amazônia, também são registrados nessa área (MOTA-FILHO et al., 2007). Essas evidências, juntamente com novos dados de NDVI reforçam a ideia de ser essa área ecotonal resultante da conjução da da ação de fatores físicos sobre uma variação de perfil topográfico entre uma depressão seca e semiárida e uma elevação úmida no interior do semiárido nordestino (SANTOS et al., 2014). Dessa forma, a única diferença relevante entre estas duas parcelas, se dá pelo do valor do NDVI da parcela $09(0,27)$ ser abaixo do esperado para as condições ambientais da área. Porém, este fato é explicado por clareiras presentes na parcela, deixando o solo arenoso exposto, fazendo o valor do referido índice diminuir. Já para a parcela 10 , o valor do NDVI marcou 0,45 , retomando ao padrão da área.

Com relação a classificação da fitofisionomia da mancha de cerrado encontrada no topo do Brejo de Saloá, é importante observar dois parâmetros mencionados por Ribeiro e Walter (2008). O primeiro diz respeito à fisionomia, definida pela estrutura e formas de crescimentos dominantes. O outro critério diz respeito aos fatores físicos do ambiente e também da composição florística. Nesse sentido, o enclave de cerrado encontrado na área de estudo se enquadra na fisionomia de um cerrado stricto senso, devido a sua estrutura (forma), como também por sua composição florística, pois foram coletadas espécies como Stigmaphyllon paralias, Tocoyena formosa, Tibouchina multiflora, Lantana camara, L. canescens, entre outras, que fazem parte da flora do cerrado stricto senso, e são citadas na literatura (BASTOS; FERREIRA, 2010; MEDEIROS, 2011; MENDONÇA, 2008; RIBEIRO; WALTER, 2008).

$O$ setor onde se encontra o enclave de cerrado, no topo do perfil topográfico, é bastante diferenciado com relação à porção da depressão 
sertaneja, principalmente no que diz respeito às condições climáticas e a composição florística da cobertura vegetal. Nesse sentido, na porção menos elevada do perfil topográfico, foram coletadas espécies como Poincianella pyramidalis, Piptadenia stipulacea, Jatropha molissima, dentre outras, típicas do bioma caatinga (PRADO, 2003).

O estabelecimento da mancha de Cerrado inserida no domínio semiárido encontra explicação na Teoria dos Refúgios. Nesse sentido, Troppmair (2006) destaca que os refúgios são áreas que podem ser florestais ou não, onde se estabelece uma biota em ambientes relativamente restritos, circundados por condições geoambientais diferenciadas, causando o impedimento de sua expansão.

No tocante à Teoria dos Refúgios, devido a uma série de glaciações ocorridas no Quaternário, a dinâmica vegetacional do Brasil passou por fases de retração e expansão florestal, ocasionando alteração na posição das caatingas e dos cerrados (AB'SABER, 2005). Devido a alternância entre climas secos e úmidos nas regiões tropicais, Conti e Furlan (2003) citam que o conjunto geobotânico brasileiro é resultado da expansão e retração das florestas, cerrados e caatingas desencadeados nos períodos de mudanças climáticas.

$\mathrm{Na}$ transição entre o Pleistoceno e Holoceno, 18 a 12 mil anos A.P, as condições climáticas fizeram com que as caatingas ocupassem uma área bem maior do que nos dias atuais, extrapolando os domínios dos biomas cerrado e amazônico. Passado esse período mais seco de expansão da caatinga, as áreas onde se verifica a presença da vegetação do tipo cerrado se deram como refúgios; já em alguns locais, a caatinga permaneceu como redutos (SILVA, 2011). Dessa forma, a Teoria dos Refúgios explica o cerrado encontrado no topo do Brejo de Saloá.

Para explicar a ocorrência de uma vegetação típica de outra província fitogeográfica, Ab'Sáber (2005) usou o princípio do enclave, ou resíduo relictual. Nesse contexto, Brejo de Saloá pode ser considerado como um enclave, uma vez que a cobertura vegetal, considerada cerrado, é cercada por outro domínio de natureza e composição completamente diferentes. Este autor ainda acrescenta que para o estabelecimento dessas espécies nesses locais, possíveis corredores teriam existido em algum tempo, provavelmente no momento geológico em que o clima era favorável para a expansão de tal vegetação.

Referente à dinâmica da expansão e retração do cerrado e da caatinga durante o Quartenário, Silva (2011) comenta que, após o período de retração das caatingas, devido às flutuações climáticas, e com um clima mais úmido, essas condições levaram a uma expansão dos cerrados. Desse modo, o autor acrescenta que os enclaves de cerrado encontrados fora do seu domínio (Brasil Central), são refúgios, interpretados como testemunhos, caracterizando-se como paleoambientes.

Além disso, destaca-se também a ocorrência de líquens da família Cladoniaceae, que são comuns em áreas de tabuleiros arenosos costeiros, no cerrado amazônico (lato senso) e no cerrado do Brasil central (senso stricto). Em estudo sobre a espécie de líquen Cladonia verticillaris, Buril et al. (2010) fez coletas da referida espécie em duas áreas de cerrado, nos tabuleiros costeiros de Alhandra (Paraíba) e, no cerrado que ocorre no brejo de Saloá (Pernambuco). Os autores corroboraram que esta espécie ocorre em áreas fitofisionomicamente semelhantes, mas climática e geograficamente distintas, inclusive traçando seu perfil genético. Este fato corrobora nossos indicativos do estabelecimento de mancha de Cerrado em Saloá, e, que em nessas condições climáticas os liquens podem ser um bioindicador de ambientes de cerrado. Em outras regiões do planeta, sobretudo as boreais, as Cladoniaceae ocorrem em solos ácidos de bosques de Pinus spp (PIZNAK; BAKOR, 2019).

O presente estudo se torna mais abrangente e esclarecedor à medida em que o recorte espacial proposto é analisado traçando um panorama fisiográfico do recorte da paisagem. Nesse sentido, abrange aspectos das unidades de relevo, dos solos, e das diferentes coberturas vegetais envolvidas nesse processo de diferenciação da vegetação ao longo do perfil topográfico. Essas características podem ser visualizadas na Figura 1, que expõe os diferentes aspectos ambientais da área estudada. As coordenadas georreferencias, utilizadas para elaboração do Perfil da Paisagem da Figura 1, estão representadas na tabela 1 . A distribuição espacial dos pontos (parcelas) ao longo dos municípios está representada no mapa 1 .

Assim, através de agrupamentos das características ambientais, tais como: tipos de vegetação, índice de aridez, tipos de solo e unidades de relevo, foi possível estabelecer um perfil esquemático de como as diferentes formações vegetais se distribuem ao longo do gradiente topográfico.

A Figura 2 apresenta um mosaico com fotografias das parcelas ao longo de todo o perfil da paisagem (parcelas 1 a 10). 
Figura 1. Perfil da Paisagem entre Águas Belas e Saloá.
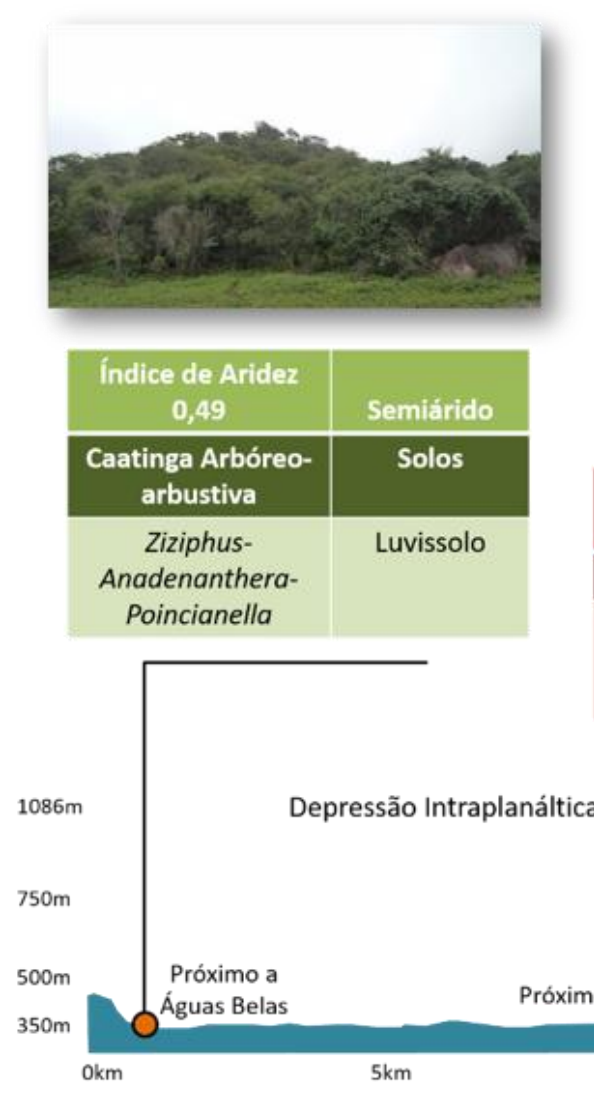

Fonte: Autores.

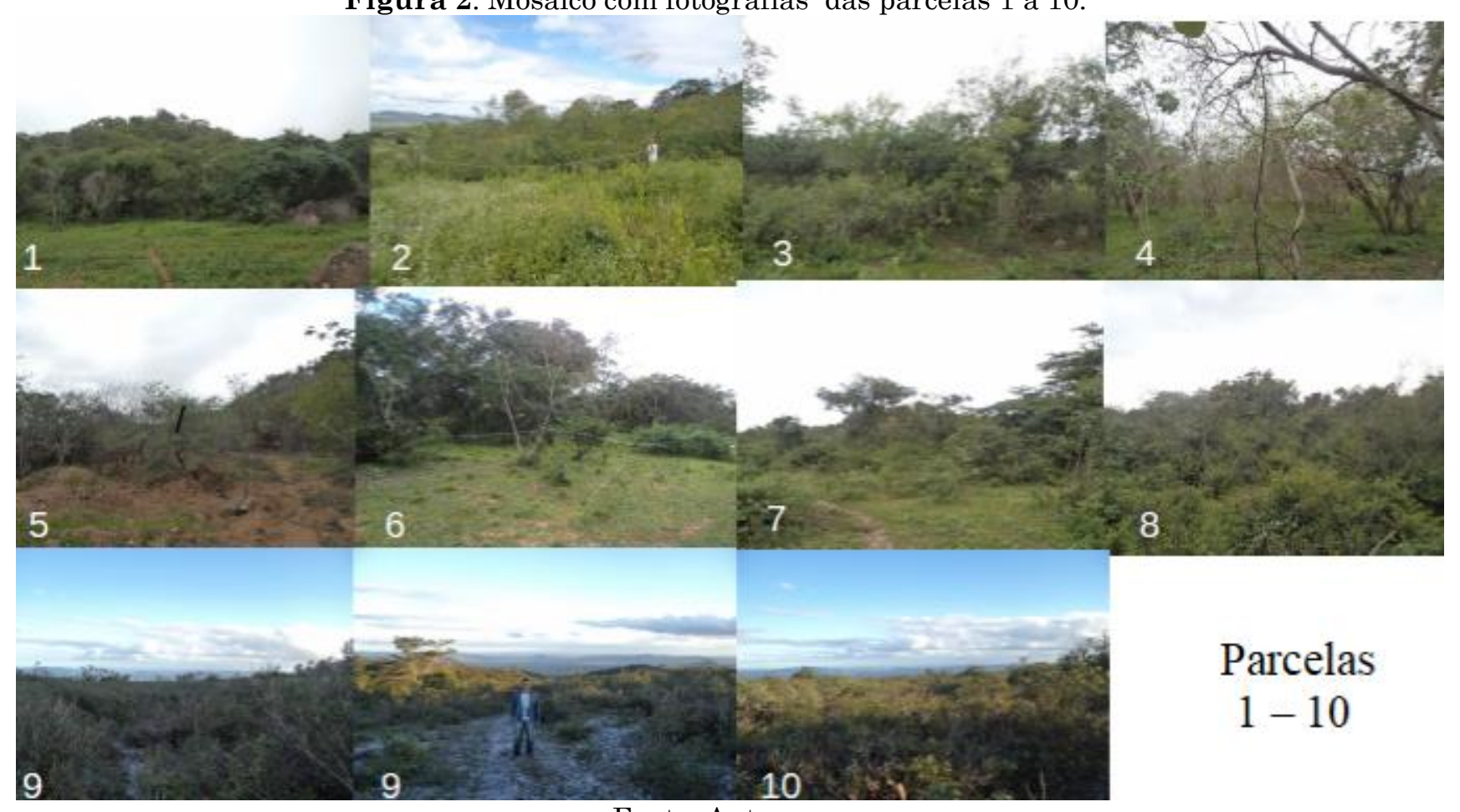

Fonte: Autores. 
Tais formações vegetais variam desde a caatinga típica de ambientes secos, passando por ambientes onde os condicionantes físicos favorecem o desenvolvimento de mata serrana, e culminando no enclave de cerrado no topo do Brejo de Saloá.

\section{CONSIDERAÇÕES FINAIS}

Ao longo do recorte espacial selecionado, que se estende desde a Depressão Interplanáltica do Alto Ipanema, nos municípios de Águas Belas e Iati, até a Cimeira Estrutural PernambucoAlagoas, onde está inserido o município de Saloá, houve uma variação na estrutura e composição da cobertura vegetal. Desta forma, devido às diversas influências dos condicionantes ambientais, sobretudo a variação de umidade ao longo do perfil topográfico, é propiciado o estabelecimento e desenvolvimentos de um verdadeiro mosaico vegetal. Este mosaico inclui o seguinte: Caatinga, típica de ambientes secos, que por vezes é arbustiva densa, em outros locais é arbustiva esparsa; Caatinga arbórea, que desenvolve em ambiente onde há um acréscimo de umidade; Matas Serranas e de Altitude; como também, tais condicionantes locais propiciam o estabelecimento de um enclave de Cerrado.

O NDVI mostrou-se bastante eficaz quanto à diferenciação dos níveis de densidade da vegetação, sobretudo quando os valores obtidos são confrontados com as quotas altimétricas do terreno. Dessa forma, auxiliam na diferenciação dos padrões da cobertura vegetal, que associados a fatores físicos locais, podem explicar a variação do mosaico dessa vegetação, sobretudo ao estabelecimento de manchas de cerrado edáfico.

\section{REFERÊNCIAS}

AB'SABER, A. N. Os Domínios de Natureza no Brasil: potencialidades paisagísticas. São Paulo: Ateliê Editorial, 3ª edição, 159 p. 2005.

ASNER, G. P.; NEPSTAD, D.; CARDINOT, G.; RAY, D. Drought stress and carbon uptake in an Amazon forest measured with spaceborne imaging spectroscopy. PNAS, v. 101, n. 16, pp. 6039-6044. 2004. https://doi.org/10.1073/pnas.0400168101

ASNER, G. P.; WARNER, A. S. Canopy shadow in Ikonos satellite observations of tropical forest and savanas. Remote
Sensing of Environment, v. 87, p. 521-533, 2003. https://doi.org/10.1016/j.rse.2003.08.006 ASRAR, G.; FUCHS M.; KANEMASU, E. T.; HATFIELD, J. L. Estimating absorbed photosynthetic radiation and leaf area index from spectral reflectance in wheat. Agronomy Journal, v. 76, pp. 300-306. 1984. https://doi.org/10.2134/agronj1984.000219620 07600020029x

BASTOS, L. M.; FERREIRA, I. M. Composições fitofisionômicas do bioma Cerrado: Estudo sobre o subsistema de Vereda. Espaço em Revista, v.12, p.99-108, 2010. Available at: https://www.revistas.ufg.br/espaco/article/vie w/17656 Accessed: May 10, 2015.

BITENCOURT, M. D.; MESQUITA Jr., H. N.; MANTOVANI, W.; BATALHA, M. A.; PIVELLO, V. R. 1997. Identificação de fisionomias de cerrado com imagem índice de vegetação. Pp. 316-320. In: L. L. Leite. \& C. H. Saito (orgs.). Contribuição ao Conhecimento Ecológico do Cerrado. Editora Universidade de Brasília, Brasília. 1997.

BURIL, M. L. L; MARTINS, M. C. B; PEREIRA, E. C. G; SILVA, N. H. Estudo comparativo da fração fenólica da imobilização em sistema de fluxo contínuo de Cladonia verticillaris (Raddi) FR. (Ascomycota: Lecanoromycetes) de duas ÁREAS DISTINTAS DE CERRADO. In: $61^{\circ}$ Congresso Nacional de Botânica. Manaus, Amazônia, Brasil. 2010.

CARVALHO JÚNIOR, O. A.; SAMPAIO, C. S.; SILVA, N. C.; COUTO JÚNIOR, A. F.; GOMES, R. A. T.; CARVALHO, A. P. F.; SHIMABUKURO, Y. E. Classificação de Padrões de Savana Usando Assinaturas Temporais NDVI do Sensor MODIS no Parque Nacional Chapada dos Veadeiros. Revista Brasileira de Geofísica. Vol. 26 (4). p. 505-517, 2008. https://doi.org/10.1590/S0102-

261X2008000400010

CONTI, J. B.; FURLAN, S. A. Geoecologia: O Clima, os Solos e a Biota. In: ROSS, J. S. (Org.). Geografia do Brasil. 4. ed. 1 reimp. São Paulo: Editora da Universidade de São Paulo. 2003.

CORRÊA, A. C. B.; TAVARES, B. A. C.; MONTEIRO, K. A.; CAVALCANTI, L. C. S.; LIRA, D. R. Megageomorfologia e Morfoestruturas do Planalto da Borborema. Revista do Instituto Geológico, n.31. São Paulo. p.35-52. 2010. 
https://doi.org/10.5935/0100-929X.20100003

HAFFER, J. Speciation in Amazonian Forest

Birds. Science, vol. 165, n. 3889. P. 131-137. 1969.

https://doi.org/10.1126/science.165.3889.131

IBGE. Manual técnico da vegetação brasileira: sistema fitogeográfico, inventário das formações florestais e campestres, técnicas e manejo de coleções botânicas, procedimentos para mapeamentos. 2a ed. IBGE-Instituto Brasileiro de Geografia e Estatística, Rio de Janeiro, 275p. 2012. Available at: https://uc.socioambiental.org/sites/uc/files/201 9-12/liv63011.pdf. Accessed: May 10, 2019.

MEDEIROS, J. de D. Guia de campo: vegetação do Cerrado 500 espécies. Ministério do Meio Ambiente/SBF, Brasília. 2011.

MENDONÇA, R. C.; FELFILI, J. M.; WALTER, B. M. T.; SILVA JÚNIOR, M. C.; REZENDE, A. V.; FILGUEIRAS, T. S.; NOGUEIRA, P. E. Flora Vascular do Cerrado. Pp. 289-556. In: S. M. SANO; S. P. ALMEIDA (eds). Cerrado: ambiente e flora. Planaltina, EMBRAPA-CPAC. 2008.

MOTA FILHO, F. O.; PEREIRA, E. C. G., LIMA, E. S.; SILVA, N. H.; FIGUEIREDO, R. C. B. Influência de poluentes atmosféricos em Belo Jardim (PE) utilizando Cladonia verticillaris (líquen) como biomonitor. Química Nova, vol. 30, No. 5, pp. 1072-1076, 2007. https://doi.org/10.1590/S010040422007000500004

MYNENI, R. B.; HALL, F. G.; SELLERS, P. J.; MARSHAK, A. L. The interpretation of spectral vegetation indexes. IEEE Transactions on Geoscience and Remote Sensing, v. 33, pp. 481-486. 1995. https://doi.org/10.1109/36.377948

NOBREGA, N. A.; RIBEIRO, S. M. A.; PEREIRA, E. C.; MARCELLI, M. M.; MARTINS, M. C. B.; FALCÃO, E. P. S.; GUSMÃO, N. B.; SILVA, N. H. Produção de compostos fenólicos a partir de células imobilizadas do líquen Parmotremaandinum (Müll. Arg.) Hale e avaliação de atividade antimicrobiana. Acta Botanica Brasilica, vol. 26 num. 1: pp. 101-107. 2012. https://doi.org/10.1590/S010233062012000100012

PEREIRA, E. C.; SANTOS, L. P.; SILVA, A. K. O.; SILVA, R. F.; SILVA, N. H.; BURIL, M. L. L.; MARTINS, M. C. B.; SANTIAGO, R.; VICENTE, C.; LEGAZ, M. E. Interaction of
Cladoniaceae lichens with Quartzarenic Neosols in Northeastern Brazil: a mini review. Revista Brasileira de Geografia Física, vol. 12 num. 06: pp. 2302-2312. 2019.

PIZNAK, M.; BACKOR, M. Lichens affect boreal forest ecology and plant metabolism. South African Journal of Botany, v.124, pp. 530 - 539. 2019. https://doi.org/10.1016/j.sajb.2019.06.025

PRADO, D. E. As Caatingas da América do Sul. In.: LEAL, I. R.; TABARELLI, M. (Eds.) Ecologia e Conservação da Caatinga. Editora Universitária: UFPE. 2003.

RIBEIRO, J. F.; WALTER, B. M. T. As principais fitofisionomias do bioma cerrado. In: SANO, S.M., ALMEIDA, S.P de. (Ed.) Cerrado: ambiente e flora. Brasília: EMBRAPA, v.1, p.152-212. 2008 .

SANTOS, L. S.; SILVA, H. P. B.; PEREIRA, E. C. G. Cerrado em área disjunta em brejo de altitude no agreste pernambucano, brasil. Boletim Goiano de Geografia. v.34, n.32, p.337-353. 2014. https://doi.org/10.5216/bgg.v34i2.31735

SILVA, M. L. A Dinâmica de Expansão e Retração de Cerrados e Caatingas no Período Quaternário: Uma Análise Segundo a Perspectiva da Teoria dos Refúgios e Redutos Florestais. Revista Brasileira de Geografia Física. v.4, p.57-73. 2011.

https://doi.org/10.26848/rbgf.v4i1.232642

SOBREVILLA, C.; BATH, P. Evaluación ecológica rápida: un manual para usuarios de América Latina y el Caribe. Washington, The Nature Conservancy. 1992.

TROPPMAIR, H. Biogeografia e Meio Ambiente. 7. ed. Rio Claro: Divisa. 2006. Available at: http://www.icmbio.gov.br/portal/images/storie s/imgs-unidades-

coservacao/naturezaemfoco.pdf Accessed: June 17, 2016. 